\title{
Broad-scale acoustic telemetry reveals long-distance movements and large home ranges for invasive lionfish on Atlantic coral reefs
}

\author{
Stephanie J. Green ${ }^{1, *}$, Jordan K. Matley ${ }^{2}$, D. Elizabeth Smith ${ }^{3}$, Bernard Castillo II $^{3}$, \\ John L. Akins ${ }^{4,5}$, Richard S. Nemeth ${ }^{6}$, Clayton Pollock ${ }^{7}$, Kynoch Reale-Munroe $^{3}$ \\ ${ }^{1}$ Department of Biological Sciences, University of Alberta, Edmonton, AB T6G 2R3, Canada \\ ${ }^{2}$ Department of Aquatic Resources, St. Francis Xavier University, Antigonish, NS B2G 2W5, Canada \\ ${ }^{3}$ College of Science \& Mathematics, University of the Virgin Islands, RR1 Box 10000 , St. Croix, USVI 00850 \\ ${ }^{4}$ Reef Environmental Education Foundation, Key Largo, Florida 33037, USA \\ ${ }^{5}$ Phillip and Patricia Frost Museum of Science, Miami, Florida 33132, USA \\ ${ }^{6}$ Center for Marine and Environmental Studies, University of the Virgin Islands, 2 John Brewers Bay, St. Thomas, USVI 00802 \\ ${ }^{7}$ National Parks Service, Buck Island Reef National Monument, Christiansted, St. Croix, USVI 008020-4611
}

\begin{abstract}
Tracking studies for invasive lionfish (Pterois volitans and P. miles) in the Western Atlantic can provide key information on habitat use to inform population control, but to date have likely underestimated home range size and movement due to constrained spatial and temporal scales. We tracked 35 acoustically tagged lionfish for >1 yr (March 2018-May 2019) within a $35 \mathrm{~km}^{2}$ acoustic array in Buck Island Reef National Monument, St. Croix, US Virgin Islands (an area $10 \times$ larger than previous studies). Tracking lionfish at this scale revealed that home range size is 3-20 times larger than previously estimated and varies more than 8-fold across individuals ( 48 000-379 $000 \mathrm{~m}^{2}$; average: $\left.101000 \mathrm{~m}^{2}\right)$, with estimates insensitive to assumptions about potential mortality for low-movement individuals. Lionfish move far greater distances than previously reported, with $37 \%$ of fish traveling $>1 \mathrm{~km}$ from the initial tagging site toward deeper habitats, and 1 individual moving $\sim 10 \mathrm{~km}$ during a $10 \mathrm{~d}$ period. Movement rates, home range size, and maximum distance traveled were not related to lionfish size $(18-35 \mathrm{~cm}$ total length) or lunar phase. Lionfish movement was lowest at night and greatest during crepuscular periods, with fish acceleration $\left(\mathrm{m} \mathrm{s}^{-2}\right)$ increasing with water temperature during these times. Our results help reconcile observed patterns of rapid recolonization following lionfish removal, and suggest complex drivers likely result in highly variable patterns of movement for similarly sized fish occupying the same habitat. Culling areas $\geq$ the average lionfish home range size identified here (i.e. $\sim 10$ ha) or habitat patches isolated by $\geq \sim 180 \mathrm{~m}$ (radius of average home range) may minimize subsequent recolonization. If the shallow-deep long-distance movements observed here are unidirectional, mesophotic habitats may require culling at relatively greater frequencies to counteract ongoing migration.
\end{abstract}

KEY WORDS: Animal movement - Home range size - Habitat use · Acoustic telemetry . Invasive species $\cdot$ Population control $\cdot$ Marine conservation

\section{INTRODUCTION}

Understanding patterns and drivers of animal movement is a fundamental pursuit in ecology with important conservation and management implications (Börger et al. 2008, van Beest et al. 2011). In

\footnotetext{
*Corresponding author: stephanie.green@ualberta.ca
}

particular, information on rates and patterns of movement can inform habitat conservation plans for populations of imperiled species (Hays et al. 2019), and guide population control and management activities for non-native species (Lennox et al. 2016). The invasion of Indo-Pacific lionfish (Pterois volitans and

(C) The authors 2021. Open Access under Creative Commons by Attribution Licence. Use, distribution and reproduction are unrestricted. Authors and original publication must be credited. 
P. miles) into coastal marine habitats in the Tropical Western Atlantic Ocean and Caribbean Sea represents a conservation issue for which information on the species' movement patterns and home range size is urgently needed to inform ongoing management. Lionfish represent the first successful introduction of marine fish from the Western Pacific Ocean to Atlantic waters (Whitfield et al. 2002, Sutherland et al. 2010), and were first reported in the Atlantic in the early 1980s, possibly as a result of aquarium releases (Semmens et al. 2004). By 2010, lionfish were established along the eastern coast of the USA throughout the Northern Caribbean region (Schofield 2010). Since then, the invasion has expanded to include the Gulf of Mexico and Southern Caribbean to the northern coast of South America (Schofield \& Akins 2019, USGS 2019), with the rate and degree of spread greater than documented before in any marine system (Côté et al. 2013).

At high densities, invasive lionfish have detrimental ecological effects on coral reef ecosystems, highlighting the need for ongoing, targeted population management (reviews of the issue by Côté et al. 2013, Hixon et al. 2016, Côté \& Smith 2018). Numerous studies have highlighted the localized effects of predation by lionfish on the recruitment, survival, biomass, and diversity of native fish species at high densities (e.g. Green et al. 2014, Albins 2015, Benkwitt 2015), as well as effects of competition with lionfish on the growth, behavior, and distribution of native reef predators (e.g. Albins 2013, Raymond et al. 2015). There are also concerns for the long-term effects of the invasion on key ecological services provided by impacted native taxa as well as on commercially important species (e.g. Lesser \& Slattery 2011, Chagaris et al. 2017). To reduce local densities of lionfish and alleviate ecological effects on invaded habitats, culling programs (in the form of manual removal of the fish from invaded habitats using spears and nets, and increasingly via traps) are underway across the invaded region (Green \& Grosholz 2021). While some work has assessed the frequency and timing of culling to maintain lionfish abundances below levels predicted to cause negative effects (e.g. Green et al. 2017, Kyne et al. 2020), relatively little work has focused on identifying the location and spatial scales at which culling is most effective. Information on patterns and drivers of lionfish movement in invaded habitats would help to identify the scale and frequency of culling required to meet management targets for suppression.

Previous studies of lionfish habitat use and movement have varied greatly in detection methods and

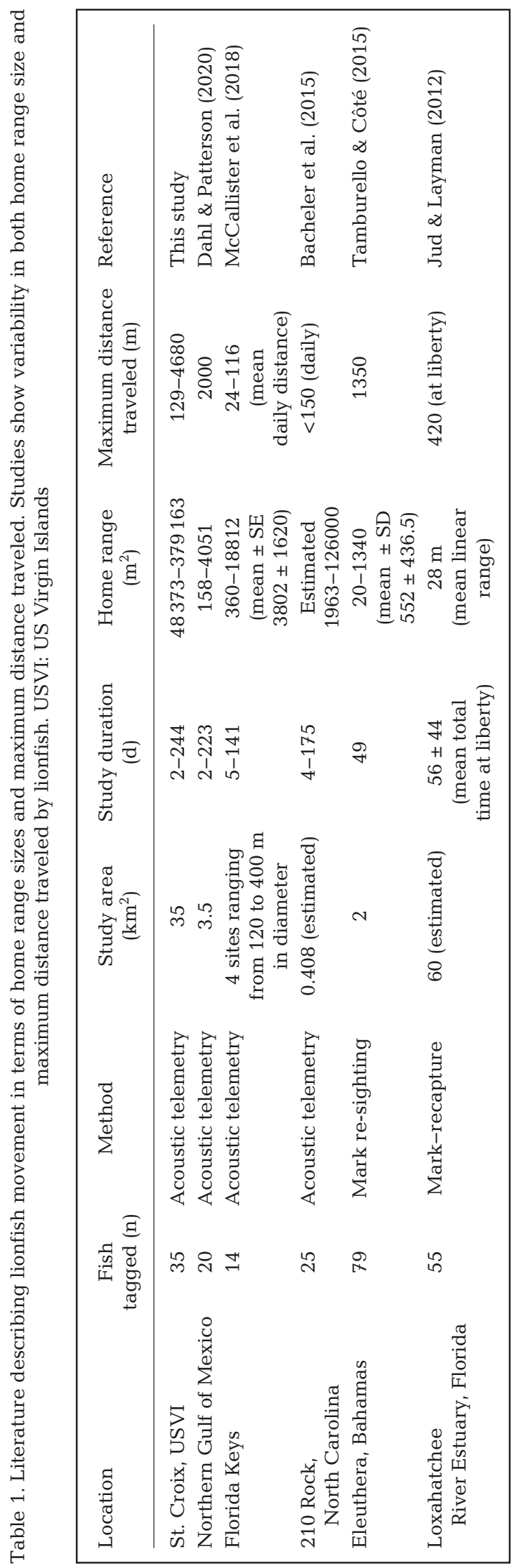


sample sizes (Table 1), but taken together, they suggest the species exhibits high site fidelity (Jud \& Layman 2012, Bacheler et al. 2015, Tamburello \& Côté 2015, McCallister et al. 2018, Dahl \& Patterson 2020). Tamburello \& Côté (2015) estimated the average lionfish home range size to be $552 \mathrm{~m}^{2}$ for 79 lionfish fitted with external visual streamer tags in the Bahamas tracked via daytime re-sighting over $7 \mathrm{wk}$ across coral reef habitats distributed within a $2 \mathrm{~km}^{2}$ area (Table 1). Bacheler et al. (2015) inferred lionfish home range to be between 1963 and $125663 \mathrm{~m}^{2}$ from detections of 25 acoustically tagged fish collected over 5 winter months from 9 receivers spaced $\sim 300 \mathrm{~m}$ apart in coastal habitats off North Carolina, USA (Table 1). McCallister et al. (2018) estimated average home range size to be $3979 \pm 1599 \mathrm{~m}^{2}$ (mean $\pm 95 \%$ kernel utilization distribution [UD]) for 14 acoustically tagged lionfish tracked for up to 4 mo over 4 sites covering a $<300$ m diameter area in the Florida Keys (Table 1). Most recently, Dahl \& Patterson (2020) estimated home range size to be between 159 and $4051 \mathrm{~m}^{2}$ for 20 acoustically tagged fish tracked up to 9 mo across a $3.5 \mathrm{~km}^{2}$ array of the Gulf Coast of Florida (Table 1).

Small home range sizes reported by these studies suggest that culling programs could be highly effective at controlling lionfish locally, with little movement of adult fish (i.e. post-settlement) from adjacent reef sites. However, high rates of recolonization have been reported in studies of lionfish removal on reefs that are larger than the majority of home range estimates (i.e. $2500 \mathrm{~m}^{2}$; Green et al. 2015; Table 1) and spaced apart at distances greater than traveled by most lionfish (i.e. >500 m; Smith et al. 2017; Table 1). Moreover, allometric scaling relationships between marine fish body size and home range also suggest that large adult lionfish ( $\geq 1000 \mathrm{~g}$ mass) might have home range sizes in the range of $\sim 150000 \mathrm{~m}^{2}$ (Tamburello \& Côté 2015), which is above the upper limit of range size estimated from previous work. These observations suggest that the restricted spatial and temporal scale of previous work on lionfish movement, presumably due to logistical constraints, may underestimate home range sizes and movements across the seascape. In particular, studies that take place over small spatial scales are more likely to underestimate home range as individuals that move 'out of bounds' are excluded from analysis. Likewise, studies that take place over short temporal scales have a reduced likelihood that observations are taking place across the range of environmental factors and conditions that influence movement across the seascape, especially if the focal species undergoes shifts in habitat occupancy as a result of environmen- tal drivers (e.g. temperature, seasons, lunar phases) and biological processes (e.g. across ontogeny).

Here, we present a full year of tracking invasive lionfish using acoustic telemetry in Buck Island Reef National Monument (BIRNM) in the US Virgin Islands, covering $35 \mathrm{~km}^{2}$ of coastal marine habitat. The scale and duration of the study should give a more complete picture of the range of variation in annual habitat use by this important invasive species. Tracking invasive lionfish across a full set of annual seasons and at a range of body size classes also allowed us to test several hypotheses about potential drivers of lionfish home range size and movement patterns.

First, studies suggest that the extent of a home range is set by the body size of the individual (Minns 1995), with home range estimates increasing significantly across fish species of increasing body size (Woolnough et al. 2009). We therefore hypothesized that lionfish body size influences movement, with larger lionfish using larger home ranges and traveling greater distances during the study period.

Second, many reef fishes, such as parrotfish and groupers, align reproductive behaviors with full moon phases and in some cases seek out particular habitats for spawning (Bolden 2000, Hamilton et al. 2008, Nemeth 2012, Rhodes et al. 2012). If the timing and location of lionfish reproduction coincides with lunar cycles, we hypothesized that lionfish would likely be more active (i.e. traveling greater distances) and show directional movement (i.e. towards particular locations) during particular lunar phases.

Third, studies of lionfish foraging behavior report periods of intense activity centered around crepuscular (dawn and dusk) periods, with periods of relative inactivity during day and night (Green et al. 2011, Cure et al. 2012). We hypothesized that rates of movement for lionfish in BIRNM will follow these diel cycles, but that this pattern may be mediated by variation in seasonal water temperature, with rates of activity lower in seasons where cooler temperatures result in lower metabolic demands.

Finally, acoustically tagged animals repeatedly detected on one or few adjacent receivers are typically assumed to represent mortality events (Klinard \& Matley 2020). However, this method is not likely appropriate for lionfish because visual tagging studies have indicated that a single individual could be highly resident (i.e. <20 m movement from tagging site) for more than 6 mo (Akins et al. 2014). We therefore explored assumptions about mortality (vs. resident behavior) for individuals with highly localized detections on estimates of average home range size, rate of movement, and maximum distance traveled 
for the species. We hypothesized that while maximum estimates of home range size and rates of movement will be unaffected by assumptions about mortality, average estimates for these properties may be higher when fish that might otherwise be assumed to represent mortality events (but could instead represent sedentary individuals) are included in our analyses.

\section{MATERIALS AND METHODS}

\subsection{Study area}

The study took place in BIRNM off of St. Croix, USVI $\left(17^{\circ} 47^{\prime} 11^{\prime \prime} \mathrm{N}, 64^{\circ} 37^{\prime} 14^{\prime \prime} \mathrm{W}\right)$. The monument includes a relatively small $\left(712000 \mathrm{~m}^{2}\right)$ and uninhabited island approximately $2.4 \mathrm{~km}$ north of St. Croix, as well as $76.2 \mathrm{~km}^{2}$ of coral reef, colonized pavement, seagrass, and sandy-bottom habitats where fishing, including for lionfish, is prohibited (Pittman et al. 2008). VR2W acoustic receivers (InnovaSea, formerly Vemco, $69 \mathrm{kHz}$ ) were installed throughout the park in depths between 5 and $60 \mathrm{~m}$ ( $\mathrm{N}=131$ receivers) and covered an area of approximately $35 \mathrm{~km}^{2}$. Lionfish collection and tagging were restricted to habitats near the center of the monument within a cluster of closely spaced receivers $(\mathrm{N}=$ 36) covering an area $\sim 0.25 \mathrm{~km}^{2}$ and located at depths of 5-8 $\mathrm{m}$ along the fringing reef and $12-18 \mathrm{~m}$ in patch reef areas south of Buck Island with a minimum of $100 \mathrm{~m}$ and maximum of $125 \mathrm{~m}$ between each (Fig. 1). The closely spaced cluster of receivers was designed as a fine-scale positioning system (FPS; formerly Vemco Positioning System) and located within the center of the broader array of 95 receivers covering $35 \mathrm{~km}^{2}$. Range testing conducted by Selby et al. (2016) within this cluster of receivers (where tagging occurred) and throughout the broader array area indicated that a receiver-transmitter distance of $100 \mathrm{~m}$ resulted in $58.2 \%$ of transmissions being detected across all habitats.

\subsection{Fish collection and tagging}

In March 2018, 40 (of 42 sighted) lionfish were captured and tagged underwater by SCUBA divers from patch $(n=30)$ and continuous fringing reef $(n=10)$ habitats south of Buck Island (Fig. 1) following methods adapted from Akins et al. (2014). Captured fish were held, unanesthetized, by divers in clear vinyl

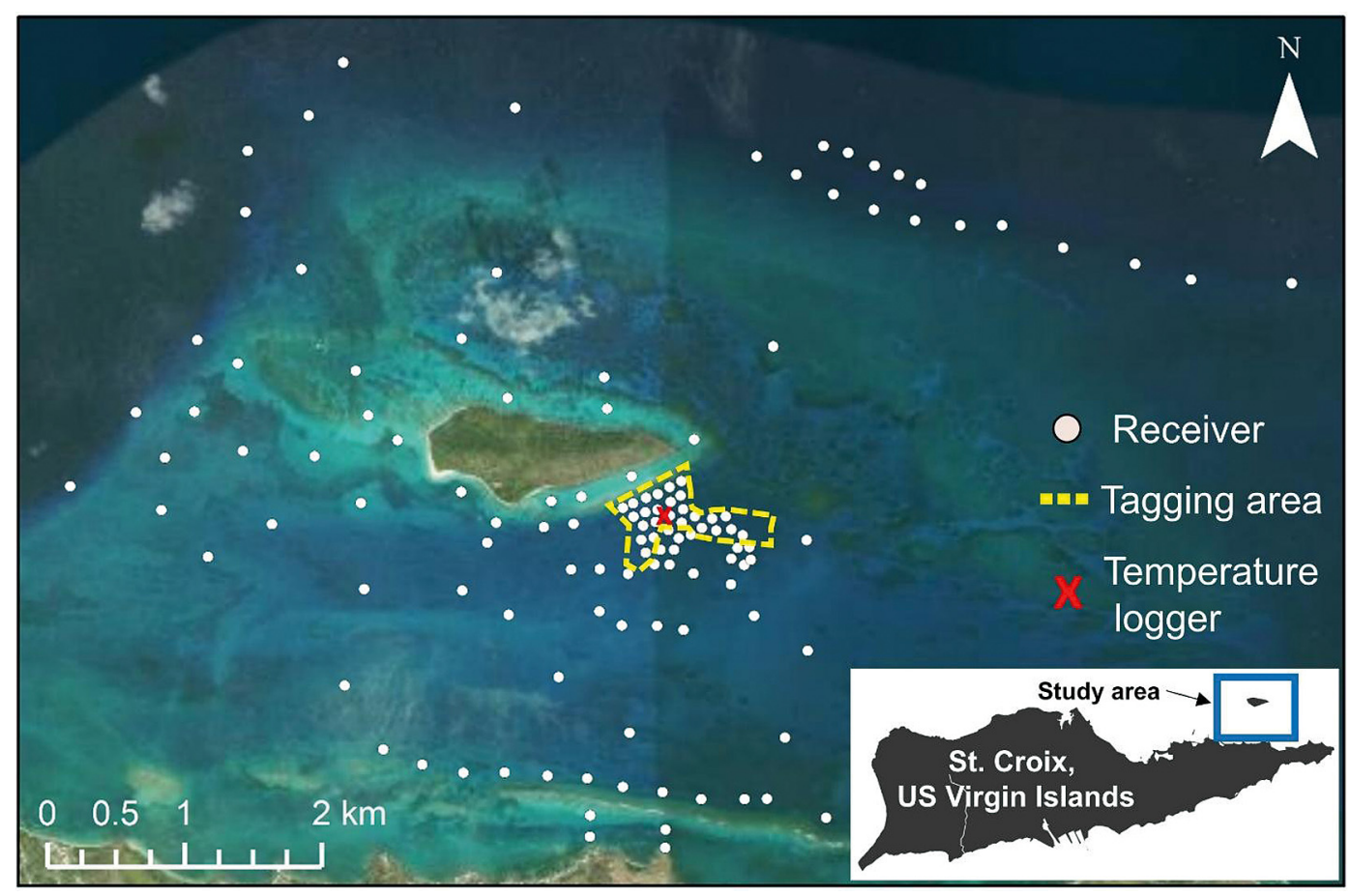

Fig. 1. Receiver array $(\mathrm{N}=131)$ within the Buck Island Reef National Monument (BIRNM) off the northeast coast of St. Croix, US Virgin Islands (USVI; inset). Six receivers deployed $\sim 20 \mathrm{~km}$ to the northeast of the tagging area did not record any detections and were omitted from the map 
nets, and fish total length ( $\mathrm{TL}, \pm 1 \mathrm{~mm}$ ) was recorded. Fish $>18 \mathrm{~cm}(\mathrm{n}=35)$ were implanted with an internal acoustic transmitter (InnovaSea, V9-2h, 110-250 s delay, $492 \mathrm{~d}$ battery life, $9 \mathrm{~mm} \times 43 \mathrm{~mm}, 3.3 \mathrm{~g}$ in water) and fitted with an external streamer tag (Floy, FTSL-73). Seven transmitters (InnovaSea, V9AP-2h, 170-270 s delay, 365 d battery life, $9 \mathrm{~mm} \times 48 \mathrm{~mm}$, $3.6 \mathrm{~g}$ in water) also included acceleration and pressure sensors to provide additional movement information. Since V9AP tags were larger and heavier, they were implanted in the larger lionfish $(>24 \mathrm{~cm})$. Fish $<18 \mathrm{~cm}$ TL $(\mathrm{n}=5)$ were tagged exclusively with an external streamer tag. Acoustic transmitters were placed within the body cavity through a 1-2 cm incision anterior of the vent. The incision was closed with dissolvable sutures (Ethicon, 18 inches [45 cm]). To insert the external streamer tag, the fish was flipped dorsal side up, and was pierced through the upper portion of the caudal peduncle with an 18-gauge, 1.5 inch intravenous needle as a guide. The streamer tag was then inserted through the opening of the needle and pulled through the fish when the needle was removed. Each streamer tag was brightly colored and labeled to allow for rapid identification and contained a unique identification number. Surgeries took 7-9 min per fish. Immediately following surgery, each fish was returned by divers using hand nets to the exact site of capture and briefly observed for any adverse reactions to surgery. All fish appeared to make a successful recovery, as characterized by recovery and maintenance of buoyancy and active swimming within 2 min following release. Fish collections and surgeries were conducted under University of the Virgin Islands Institutional Animal Care and Use Committee permit 949107 and National Park Service research permits BUIS-00072 and BUIS-2016-SCI-0004.

\subsection{Data analysis}

\subsubsection{Data filtering}

Archived transmitter detection data were downloaded from all receivers in May 2018, November 2018, and May 2019 with VUE software (version 2.6.0). All following data organization and analyses were conducted using $\mathrm{R}$ version 3.6.1 (R Core Team 2019). Raw detections underwent several filtering steps prior to data analysis. First, false detections resulting in unknown tag IDs were removed from the dataset, as well as potential false detections arising from erroneous detections matching IDs of tagged fish. Instances of the latter were identified as individual detections occurring remotely in space or time without demonstrating any sequential movement pathways (e.g. a singular detection observed several kms away from where the individual was routinely detected during the same period). Second, data from the first $24 \mathrm{~h}$ after tagging were removed from spatial analyses, unless stated otherwise, to allow for a recovery period from surgery where behavior may be unduly affected (Fig. 2). Third, data from individuals were excluded if they were detected on less than 8 unique days after tagging to avoid interpreting data from under-represented lionfish (Table 2, Fig. 2). Finally, we removed detection data from individuals that were associated with either a dropped tag or mortality event based on acceleration sensor values that were stagnant near zero through time. Of the 7 individuals tagged with sensor-enabled transmitters (i.e. tracking acceleration and depth), data from 5 individuals were dropped from analysis due to consistent acceleration values $<0.1 \mathrm{~m} \mathrm{~s}^{-2}$ (i.e. at $\sim 0 \mathrm{~m} \mathrm{~s}^{-2}$ ) and limited depth variation, suggesting that these fish either expelled their tags, were consumed and the transmitter was dropped within detection range of receivers, or died by other means (Table 2, Fig. 2; Fig. S1 in the Supplement at www.int-res.com/articles/ suppl/m673p117_supp.pdf).

\subsubsection{Mortality scenarios}

Initially, we considered that animals repeatedly detected on one or few adjacent receivers represented mortality events (Klinard \& Matley 2020). However, this method is not likely appropriate for lionfish because visual tagging studies have indicated that a single individual could be resident on the same patch reef (i.e. $<20 \mathrm{~m}$ movement from the tagging site) for more than 6 mo (Akins et al. 2014). Thus, individuals may be highly resident to small areas relative to the detection range of receivers, causing difficulty in distinguishing between ejected tags/mortalities and sedentary individuals. Because it was not always possible to confirm the fate of individuals in these instances, i.e. distinguish between a mortality event or highly resident behavior (hereafter referred to as 'highly restricted detections'), we investigated 2 scenarios (high survival and low survival) throughout this study, representing detection data from different numbers of individuals included in calculations of movement and home range. The high survival scenario represented the assumption that highly restricted detections originated from liv- 
ing individuals with low movement rates, with all detection data (after initial filtering steps described above) incorporated in analyses. Conversely, the low survival scenario assumed that highly restricted detections were from ejected tags or dead individuals, with data from these individuals excluded from analyses (see next paragraph).

We identified highly restricted detections by first calculating the maximum distance a stationary tag could be detected in the array using detections from the 5 individuals equipped with both acoustic transmitters and acceleration sensors for which mortality events had occurred based on acceleration values consistently $<0.1 \mathrm{~m} \mathrm{~s}^{-2}$, which was estimated to be $\sim 175 \mathrm{~m}$. We then used this distance when evaluating transmitter location data at a weekly scale for all tagged fish. Specifically, during weeks when each animal's transmitter was detected on receivers greater than $175 \mathrm{~m}$ apart, the animal was deemed to be alive during that period (and thus included in all analyses; Fig. 2); alternatively, if the transmitter was only detected on receivers less than $175 \mathrm{~m}$ apart (i.e. a highly restricted detection), the animal was included in the high survival scenario, but excluded from the low survival scenario, due to the possibility of a mortality event (Fig. 2). Since these classifications were conducted weekly, all periods prior to the last week with detections >175 $\mathrm{m}$ apart were identified as 'living' and any following highly restricted detections were either incorporated (high survival scenario) or excluded (low survival scenario). We chose the described approach of identifying possible mortality events as opposed to setting distance limits by traditional range testing techniques (e.g. Kessel et al. 2014) because sentinel tags that were deployed within the array, as part of another study objective, were deployed relatively high in the water column. This led to overestimates of detection range when compared with tagged lionfish that remained near the substrate in rugose habitat where detection efficiency was reduced. Consequently, the use of dropped tags was more representative of lionfish locations, and although small shifts due to currents or tide are possi- ble, the effect was minimal because designations were conducted weekly.

We then conducted all further analyses for both high and low survival scenarios, in order to help us to explore the effect of assumptions about the fate of animals (i.e. mortality events) versus animal behavior (i.e. sedentary habits) on patterns of movement and home range generated from telemetry data (Klinard \& Matley 2020). In particular, the high survival scenario may underestimate the average home range size, rate of movement, and distance moved for this species, because fish that have died (and thus are not moving) may be included in the analysis. Conversely, the low survival scenario may overestimate the average home range size, rate of movement, and distance moved if resident fish are erroneously assumed to have died and removed from analyses.

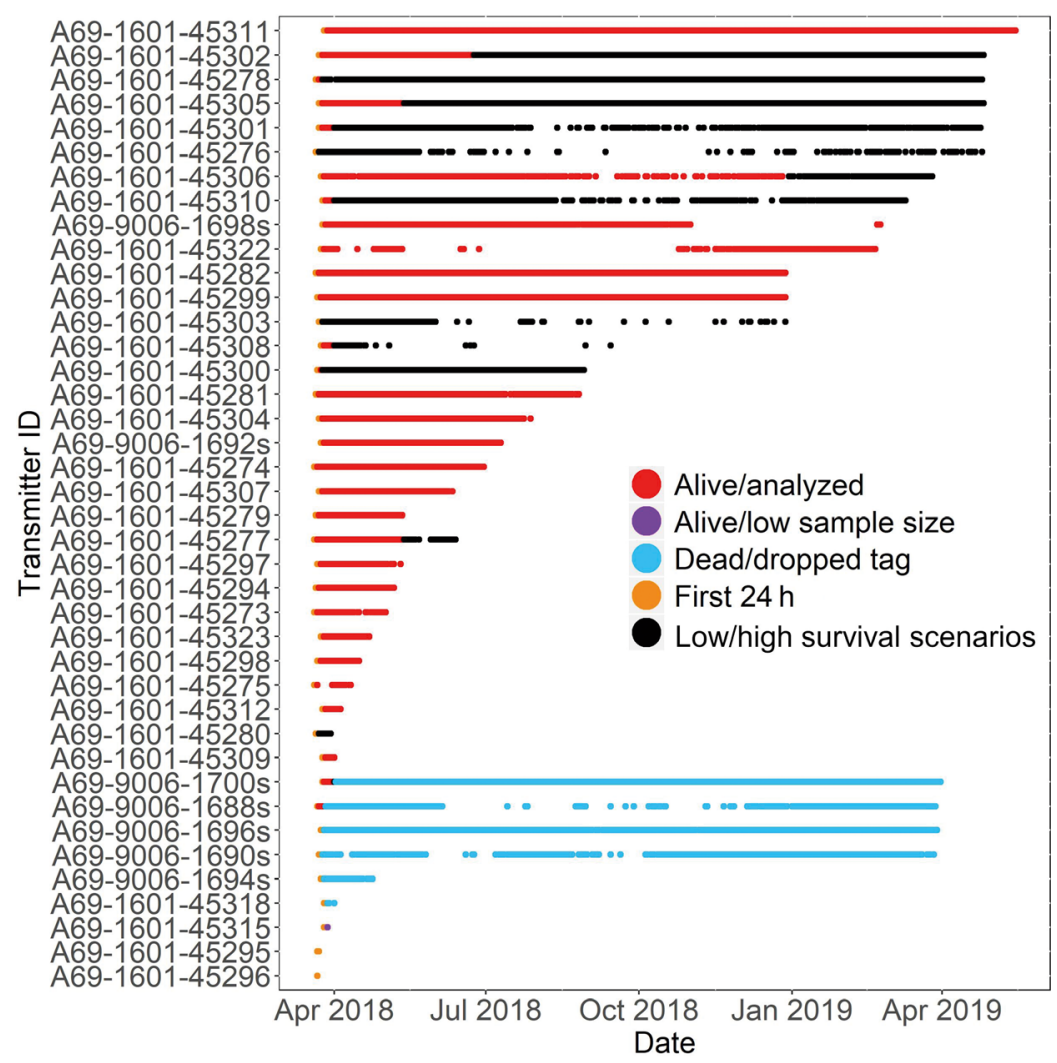

Fig. 2. Detections of acoustically tagged lionfish within the $35 \mathrm{~km}^{2}$ BIRNM array off St. Croix, USVI, across the study period. Colors represent the various filtering stages applied to detection data prior to analysis of home range and movement. Detections collected for all fish $<24 \mathrm{~h}$ from tagging (orange), from any evident mortality event based on acceleration sensor data (blue; acceleration $<0.1 \mathrm{~m} \mathrm{~s}^{-2}$ ), and for fish detected on fewer than $8 \mathrm{~d}$ after tagging (purple) were excluded from our analyses. Fish detected $>175 \mathrm{~m}$ apart within $1 \mathrm{wk}$ (red) were designated as living and were included in all analyses. Weekly detections $<175 \mathrm{~m}$ apart (black) represented potential mortality events and were excluded in the low survival scenario but included in the high survival scenario of each analysis 


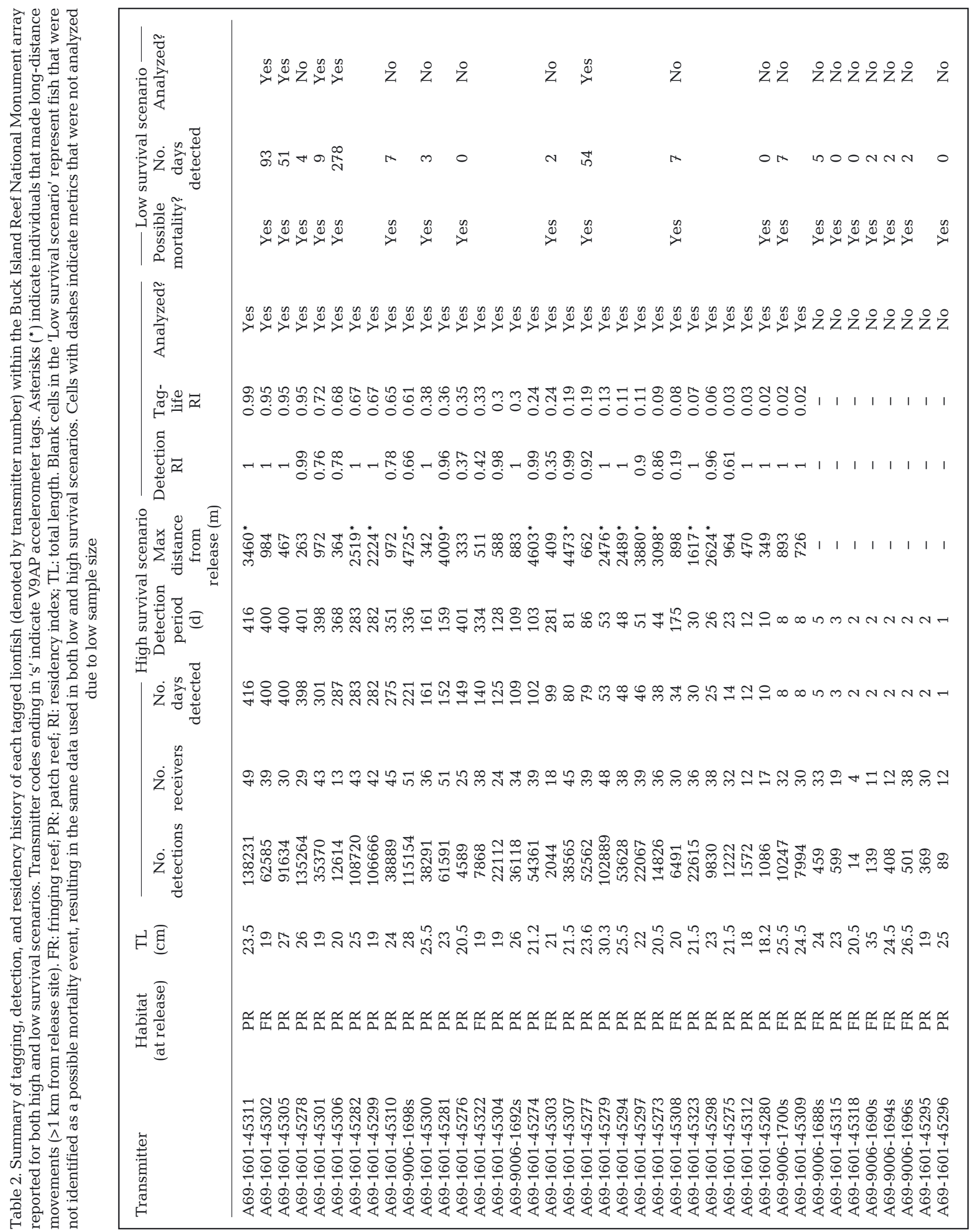




\subsubsection{Residency}

For both scenarios (i.e. high survival and low survival) we calculated 2 different residency indices (RIs) to indicate individual presence within the receiver array (i.e. study area) through time. The first, hereafter referred to as the 'detection $\mathrm{RI}^{\prime}$, was defined as the number of unique days with detections (including the release day) divided by the number of days between the first and last detection. The second RI was referred to as the 'tag-life RI' and was calculated as the number of unique days detected divided by either the number of days expected in the battery life of the tag (e.g. $365 \mathrm{~d}$ for sensor tags), the number of days in the study period (e.g. the study period was 420 d, i.e. shorter than the battery life of non-sensor tags), or number of days until the tag was deemed dead/dropped, whichever option was shorter in duration. Both indices required at least 2 detections in a day to be considered present to reduce the possible inclusion of false detections (Simpfendorfer et al. 2015). Two RIs were used because they provide different representations of presence within the array; for example, detection RI provides information relating to presence only during the period in which an individual is using areas with receivers, whereas taglife RI incorporates absence after the animal was last detected within the array area.

\subsubsection{Long-distance movements}

We evaluated the relationship between lionfish size (TL) and maximum distance moved (i.e. from release location) via linear regression. We also summarized spatial trends in the timing and location of movements for fish that traveled $\geq 1 \mathrm{~km}$ from their release location (considered 'long-distance movement' based on existing knowledge of lionfish movement patterns). These movements were examined qualitatively in relation to time of year and lunar phases to explore the possibility of spawning- (or feeding)-related movement cues tied to moon phase, as for other reef fishes (Nemeth 2009). We calculated speed during these movements based on the sum of distances between the last position before a long-distance movement and the first position in the new area of detection (divided by the sum of durations between the long-distance detections). As the pathway of movement between receivers is unclear, this rate, calculated as a straight line, likely reflects the minimum speed that individuals traveled. This metric was also used to explore possible predation events of tagged lionfish (i.e. long-distance movements faster than expected for this species).

\subsubsection{Rates and drivers of movement}

For lionfish detected on 8 or more days at any time following release, we estimated activity levels, quantified as rates of movement. Rates of movement were calculated as the speed $\left(\mathrm{m} \mathrm{s}^{-1}\right)$ of movements over the course of at least $1 \mathrm{~h}$ when detected consecutively at 10 min intervals (i.e. at least 6 intervals of $10 \mathrm{~min}$ had to be included). To calculate speed, we first estimated average location for each fish every 10 min as centers of activity (COAs; Simpfendorfer et al. 2002). COAs are calculated by taking the mean position of all detections from receiver locations during a specified time interval, providing an estimated location during each period which helps account for receivers with overlapping detection ranges (i.e. pseudo-replication from multiple receivers detecting singular transmissions) and drift in receiver clocks. The distances (in $\mathrm{m}$ ) between each consecutive COA location (every $10 \mathrm{~min}$ ) were then added together and the sum was divided by the total time and converted to $\mathrm{m} \mathrm{s}^{-1}$. Acceleration values from the 2 transmitters with acceptable acceleration data (i.e. registering $>0.1 \mathrm{~m} \mathrm{~s}^{-2}$, indicative of movement of live fish; Fig. S1 in the Supplement) were averaged each 10 min to compare with rates of movement estimated from COA positions over time, although it should be noted that these metrics represent different aspects of activity (e.g. longer-term speed [rates of movement] vs. shorter-term acceleration).

Next, we created 2 linear mixed effects models (LMMs; i.e. with Gaussian distributions) to determine whether rates of movement were influenced by biological and environmental factors: one model for rate of movement under the low survival scenario and a second model for movement under the high survival scenario. We checked our response data (rates of movement) for each model for normal distribution and homogeneity of residuals prior to analysis, and logtransformed when necessary. We included in each model the following explanatory variables, which were all present in model selection explorations (i.e. present in at least 1 model with the difference in corrected Akaike's information criterion $\triangle \mathrm{AICc}<2$ ): diel period (dawn, day, dusk, night), moon phase (new, waxing, full, waning), capture location (fringing or patch reef), TL of the individual, and water temperature. Dawn and dusk diel periods were defined as the hourly periods on each side of sunrise and sunset, re- 
spectively, which were calculated locally using the R package 'maptools' (Bivand \& Lewin-Koh 2019). Day and night diel periods consisted of the time post-sunrise/pre-sunset and post-sunset/pre-sunrise, respectively. Rate of movement estimates were only retained for analysis when they occurred fully within a diel period (i.e. not between 2 different diel periods). Moon phases were designated using the R package 'lunar' (Lazaridis 2014). Water temperature was measured hourly within the center of the tagging area $(16 \mathrm{~m}$ depth; U22-001 $\mathrm{HOBO}^{\circledR}$ Water Temp Pro v2; Onset Computer; Fig. 1), and all measurements were averaged during each corresponding period in which rates of movement were estimated. The $\mathrm{R}$ package 'nlme' (Pinheiro et al. 2019) was used to run LMMs with transmitter ID as a random variable and a firstorder auto-correlation structure built in to account for serially auto-correlated data. Correlation among explanatory variables was tested using variance inflation factors (R package 'car'; Fox \& Weisberg 2019), which indicated no issues (i.e. variance inflation factor $\leq 3$ ). We also included an interaction effect between diel period and water temperature because we predicted temperature may influence rates of movement differentially depending on the activities lionfish conduct (i.e. crepuscular feeding vs. mid-day resting) and after preliminary data exploration indicated it was contributory. We also conducted a similar LMM with the 10 min mean acceleration sensor data (excluding size and habitat because there were only 2 individuals) for comparison. Differences were considered significant when $\mathrm{p}<0.05$.

\subsubsection{Home range size}

We quantified home ranges by kernel density estimates (KDEs) using the package 'adehabitatHR' (Calenge 2006) for both high and low survival scenarios. The KDE approach was selected over others such as Brownian bridge movement models, which incorporate movement corridors in space use estimates (e.g. Becker et al. 2016), because the majority of receivers were located south of Buck Island in a relatively small area with overlapping detection ranges, negating the utility of movement corridors. The remaining receivers were sparsely arranged over a large area, which also made it difficult to identify pathways between receivers, especially when time differences were large. In general, we found the KDE approach to be more robust to uncertainty in lionfish locations between detections and also more readily comparable to other lionfish studies (e.g. Dahl \& Pat- terson 2020), which typically used the same approach to estimate home range sizes. The locations used for KDEs were estimated from 30 min COAs, which represent the average location where individuals were present every 30 min (Simpfendorfer et al. 2002). We selected UDs at 50 and $95 \%$ to represent the core use areas and extent of space use, respectively. We selected a smoothing factor $(h)$ of 50 for UD estimates after fitting different smoothers to visually optimize contour levels (e.g. values that were too high overestimated receiver detection ranges as demonstrated by overlapping with adjacent 'unused' receivers; values that were too low underestimated expected detection ranges and resulted in highly disjointed polygons) as suggested by Calenge (2006). We used a paired $t$-test to test for differences between the home range size for each individual generated from the high survival and low survival scenarios for 50 and $95 \%$ UDs separately. We also constructed separate general linear models (GLMs) for high survival and low survival scenarios to test if the TL (in $\mathrm{cm}$ ) of lionfish and the number of days each fish was detected (2 explanatory variables) affected home range size as estimated by the size of 50 and 95\% UDs separately (response variables). Data were assessed for normality and homoscedasticity as described above. Finally, we plotted UDs to show specific areas used, as well as overlap among individuals.

\section{RESULTS}

We tracked 35 tagged lionfish ranging in size from 18 to $35 \mathrm{~cm}$ TL $(23.07 \pm 3.62 \mathrm{~cm} \mathrm{TL}$; mean $\pm \mathrm{SD})$ from 20 March 2018 to 15 May 2019 (14 mo) over an area of approximately $35.6 \mathrm{~km}^{2}$ (Table 2, Fig. 2). Fish with V9 tags were $22.1 \pm 2.91 \mathrm{~cm}$ TL (range $=18-30.3 \mathrm{~cm}$ TL) and fish with V9AP tags were $27.1 \pm 3.74 \mathrm{~cm}$ TL (range $=24-35 \mathrm{~cm}$ TL) (Table 1). After initial data filtering, the high survival scenario included 1417695 detections from 32 individuals (27 initially tagged on patch reefs and 5 on fringing reefs), and the low survival scenario included 1005667 detections from 24 individuals (21 tagged on patch reefs and 3 on fringing reefs; Table 2$)$. The mean $( \pm \mathrm{SD})$ water temperature within the main receiver cluster was $27.6 \pm 0.9^{\circ} \mathrm{C}$ (range: $26.0-29.4^{\circ} \mathrm{C}$ )

\subsection{Residency and long-distance movements}

Lionfish were highly resident within the BIRNM array during their detection periods (i.e. number of days between first and last detection), with a mean 
detection RI of 0.86 (SD: 0.23; range: 0.19-1) for the high survival scenario, and with individuals being detected for up to $416 \mathrm{~d}$ (Table 2). The mean tag-life RI (i.e. detection days relative to expected duration of tag battery life, study period, or period that the individual was deemed alive) was 0.36 (SD: 0.31; range: 0.02-0.99) for the high survival scenario (Table 2). Nineteen of the 32 individuals (59\%) for the high survival scenario remained within the primary tagging area throughout their detection periods, while the remaining 13 fish (41\%) moved into other adjacent habitats or made long-distance movements within the BIRNM array.

Maximum distances traveled varied greatly among tagged fish, with 22 individuals ( $63 \%$ ) moving $<1 \mathrm{~km}$ from their tagging locations, while 13 individuals $(37 \%)$ were detected making long-distance movements $>1 \mathrm{~km}$ from the main study array to several different locations within the greater BIRNM array (mean \pm SD long-distance movement: $3.4 \pm 2.3 \mathrm{~km}$; Fig. 3). The maximum distance any fish traveled within the BIRNM array from the location of tagging was $\sim 10 \mathrm{~km}$, which occurred during an $11 \mathrm{~d}$ period (Fig. 3; ID 45297). Of the 13 individuals making longdistance movements, 9 individuals traveled up to $3 \mathrm{~km}$ after leaving the primary tagging area, 2 traveled between 3 and $5 \mathrm{~km}$, and 2 traveled $>5 \mathrm{~km}$ (Fig. 3). Long-distance movements occurred in a variety of directions; 6 individuals exhibited westward movements, 2 moved to the southwest, 4 individuals moved to the northeast of the BIRNM array, and 1 traveled to the southeast (Fig. 3). The majority of these movements were towards receiver locations along the insular shelf edge in northern St. Croix representing mesophotic reef habitats $>40 \mathrm{~m}$ depth. There was no discernible pattern of drivers for these movements relative to time of year, although almost half of these movements (6 of 13 fish; Fig. 4) occurred during the waning phase of the moon and during summer months ( 7 of 13 fish from May to September; Fig. 4). Among individuals that made long distance movements ( $>1 \mathrm{~km}$ from tagging site), we estimated maximum average speed to be $0.26 \mathrm{~m} \mathrm{~s}^{-1}$ during a $2 \mathrm{~h}$ period (ID 45279), which is within the range observed from visual observations of the species while in transit between habitats (Green et al. 2011). There was no relationship between maximum distance detected from the release location and lionfish size (TL; linear regression: $\mathrm{r}^{2}=0.03, \mathrm{p}=0.301$ ).

\subsection{Rates and drivers of movement}

Tagged lionfish movement speeds averaged $\sim 0.051 \mathrm{~m} \mathrm{~s}^{-1}$ (high survival) and $\sim 0.063 \mathrm{~m} \mathrm{~s}^{-1}$ (low survival; Table 3) across the study period; these rates differed significantly among diel periods (high survival: $F_{3,10741}=399.4, \mathrm{p}<0.001$; low survival: $F_{3,8475}=426.0$, $\mathrm{p}<0.001$ ) and were highest during dawn (high: mean \pm SD: $0.091 \pm 0.047 \mathrm{~m} \mathrm{~s}^{-1}$, low: $0.098 \pm 0.045 \mathrm{~m} \mathrm{~s}^{-1}$ ) and dusk (high: $0.074 \pm 0.043 \mathrm{~m} \mathrm{~s}^{-1}$, low: $0.081 \pm 0.041 \mathrm{~m}$ $\mathrm{s}^{-1}$ ) compared to day (high: $0.069 \pm 0.052 \mathrm{~m} \mathrm{~s}^{-1}$, low: $0.077 \pm 0.053 \mathrm{~m} \mathrm{~s}^{-1}$ ) and night (high: $0.052 \pm 0.036 \mathrm{~m}$ $\mathrm{s}^{-1}$, low: $0.057 \pm 0.037 \mathrm{~m} \mathrm{~s}^{-1}$ ) in both survival scenarios (Fig. 4). Additionally, temperature interacted with diel periods (high survival: $F_{3,10741}=40.4, \mathrm{p}<0.001$; low survival: $F_{3,8475}=12.6, \mathrm{p}<0.001$ ), in which rates of movement at night decreased with temperature,

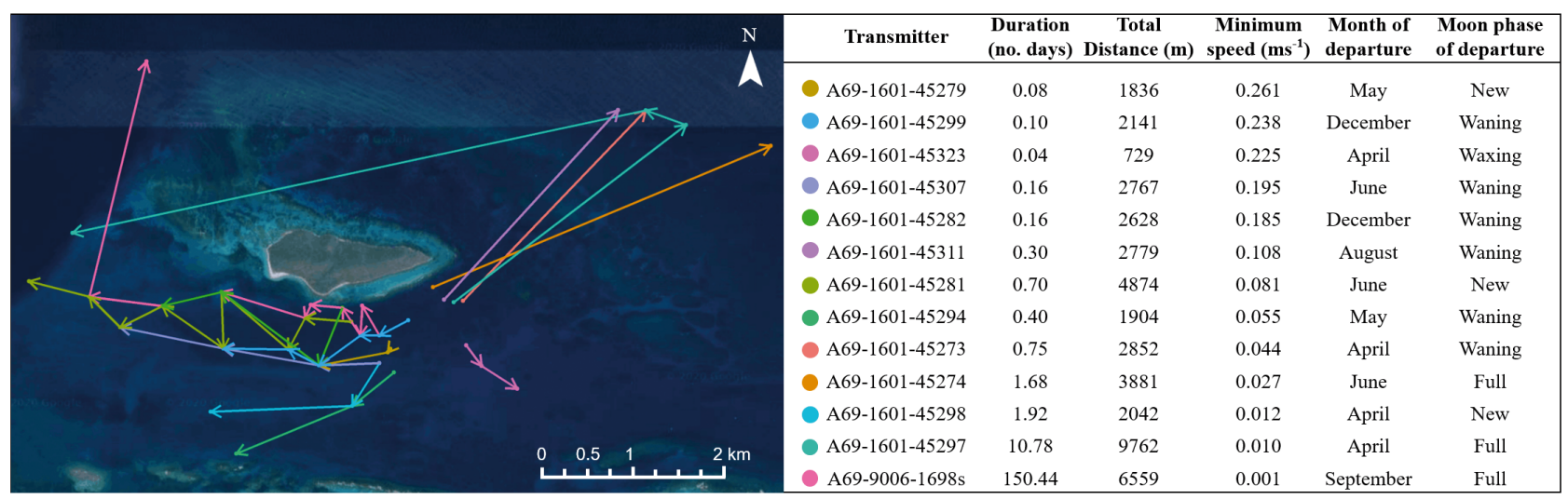

Fig. 3. Summary of long-distance movements ( $>1 \mathrm{~km}$ from location of tagging) by invasive lionfish tracked within the $35 \mathrm{~km}^{2}$ BIRNM acoustic array off St. Croix, USVI. Arrows indicate the direction of travel, as well as different areas in which individuals were detected during these movements. These data did not include detections on adjacent receivers $<200 \mathrm{~m}$ for simplification. Minimum speed was calculated based on the sum of distances and durations between each movement segment (i.e. each line/arrow combination) 

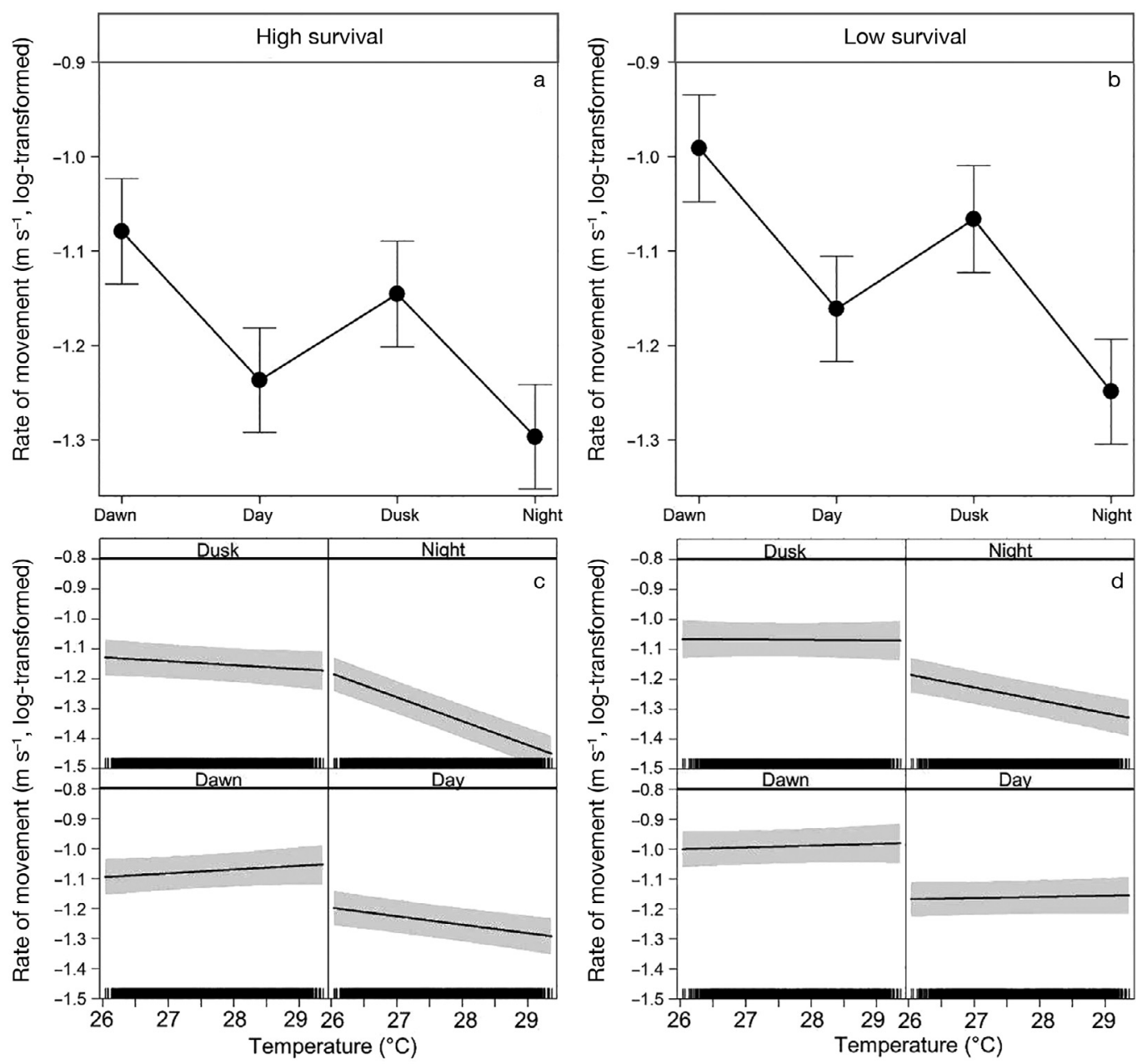

Fig. 4. Effects of $(a, b)$ time of day and $(c, d)$ temperature by time of day on mean rates of movement for high $(a, c)$ and low $(b, d)$ survival scenarios for invasive lionfish tracked within the $35 \mathrm{~km}^{2}$ BIRNM acoustic array off St. Croix, USVI. Black lines surrounded by shaded areas (continuous variables) and points with error bars (discrete variables) represent the pointwise $95 \%$ confidence band of fitted values based on standard errors, respectively, from LMMs. Vertical lines (rug-plot) above $x$-axis (in $\mathrm{C}$ and d) represent observations recorded at different temperatures

whereas other periods typically remained consistent (Fig. 4). While limited to only 2 individuals with sensors, diel acceleration trends were similar to rates of movement identified above (i.e. activity highest at dawn/dusk, lowest at night). Also, night activity levels remained constant across water temperatures, unlike other diel periods in which water temperature was positively associated with acceleration (Fig. S2 in the Supplement). Interestingly, lionfish size, habitat type, and moon phase were not significant drivers of rates of movement ( $p>0.05$; Fig. S3).

\subsection{Home range size}

Home range size and location varied greatly among lionfish, but was far greater than observed previously, with home range extent (i.e. $95 \%$ UDs) ranging from 48373 to $379163 \mathrm{~m}^{2}$ and 50164 to $379163 \mathrm{~m}^{2}$ for the high and low survival scenarios, respectively (Table 1). Mean home range estimates were larger for the low survival scenario $(95 \%$ UD mean \pm SD: $121512 \pm 67037 \mathrm{~m}^{2} ; 50 \%$ UD: $23848 \pm 10293 \mathrm{~m}^{2}$ ) relative to the high survival scenario (95\% UD mean \pm SD: $105588 \pm 66398 \mathrm{~m}^{2}{ }_{i} 50 \%$ UD: $21320 \pm 10459 \mathrm{~m}^{2}$; Fig. 5, Table 3); however, estimates for the 2 scenarios were not significantly different from one another (95\% UD: $t=0.59, \mathrm{df}=24, \mathrm{p}=0.56 ; 50 \%$ UD: $t=0.49$, $\mathrm{df}=24, \mathrm{p}=0.63)$. Most individuals remained near where they were tagged and released, as demonstrated by the high overlap in home range in the primary tagging area (e.g. up to 22 individuals within overlapping $95 \%$ UDs of high survival scenario; Fig. 6). Estimates of 50 and $95 \%$ UD were highly cor- 
Table 3. Summary of rates of movement $\left(\mathrm{m} \mathrm{s}^{-1}\right)$ and 50 and $95 \%$ home range sizes for individual lionfish reported for both high and low survival scenarios. UD: utilization distribution; COA: center of activity. Metrics for low survival scenarios were not calculated for some individuals (i.e. blank cells) because of low sample size

\begin{tabular}{|c|c|c|c|c|c|c|c|c|c|c|}
\hline \multirow{3}{*}{ Transmitter } & \multicolumn{4}{|c|}{ Rate of movement } & \multicolumn{4}{|c|}{$50 \%$ UD $\left(\mathrm{m}^{2}\right)$} & \multicolumn{2}{|c|}{$95 \%$ UD $\left(\mathrm{m}^{2}\right)$} \\
\hline & \multicolumn{2}{|c|}{ High survival } & \multicolumn{2}{|c|}{ Low survival } & \multicolumn{2}{|c|}{ High survival } & \multicolumn{2}{|c|}{ Low survival } & \multirow{2}{*}{$\begin{array}{l}\text { High } \\
\text { UD }\end{array}$} & \multirow{2}{*}{$\begin{array}{l}\text { Low } \\
\text { UD }\end{array}$} \\
\hline & $\begin{array}{c}\text { No. } \\
\text { consecutive } \\
\text { movements }\end{array}$ & Rate & $\begin{array}{c}\text { No. } \\
\text { consecutive } \\
\text { movements }\end{array}$ & Rate & $\begin{array}{c}\text { No. } \\
\text { COA } \\
\text { locations }\end{array}$ & UD & $\begin{array}{c}\text { No. } \\
\text { COA } \\
\text { locations }\end{array}$ & UD & & \\
\hline A69-1601-45311 & 1555 & 0.087 & 1555 & 0.087 & 14041 & 61669 & 14041 & 61669 & 379163 & 379163 \\
\hline A69-1601-45302 & 1310 & 0.020 & 383 & 0.050 & 16407 & 11435 & 3923 & 13326 & 52647 & 66516 \\
\hline A69-1601-45305 & 1710 & 0.009 & 129 & 0.083 & 16370 & 11448 & 1251 & 20383 & 53905 & 87098 \\
\hline A69-1601-45278 & 2019 & 0.007 & & & 17083 & 11245 & & & 49646 & \\
\hline A69-1601-45301 & 400 & 0.043 & 42 & 0.086 & 5666 & 13435 & 365 & 15073 & 64734 & 92219 \\
\hline A69-1601-45306 & 195 & 0.029 & 195 & 0.029 & 4017 & 13835 & 3433 & 14448 & 65512 & 66868 \\
\hline A69-1601-45282 & 1283 & 0.056 & 1283 & 0.056 & 9840 & 15831 & 9840 & 15831 & 82228 & 82228 \\
\hline A69-1601-45299 & 1213 & 0.060 & 1213 & 0.060 & 10531 & 25406 & 10531 & 25406 & 117322 & 117322 \\
\hline A69-1601-45310 & 430 & 0.064 & & & 5673 & 14944 & & & 65094 & \\
\hline A69-9006-1698s & 904 & 0.041 & 904 & 0.041 & 7661 & 36619 & 7661 & 36619 & 211269 & 211269 \\
\hline A69-1601-45300 & 801 & 0.010 & & & 6964 & 11028 & & & 48373 & \\
\hline A69-1601-45281 & 469 & 0.071 & 469 & 0.071 & 3971 & 30537 & 3971 & 30537 & 188651 & 188651 \\
\hline A69-1601-45276 & 40 & 0.055 & & & 1574 & 21690 & & & 81009 & \\
\hline A69-1601-45322 & 56 & 0.048 & 56 & 0.048 & 1690 & 14111 & 1690 & 14111 & 68629 & 68629 \\
\hline A69-1601-45304 & 264 & 0.054 & 264 & 0.054 & 3177 & 17251 & 3177 & 17251 & 74378 & 74378 \\
\hline A69-9006-1692s & 432 & 0.039 & 432 & 0.039 & 4232 & 30810 & 4232 & 30810 & 182679 & 182679 \\
\hline A69-1601-45274 & 529 & 0.075 & 529 & 0.075 & 4017 & 28380 & 4017 & 28380 & 125835 & 125835 \\
\hline A69-1601-45303 & 13 & 0.030 & & & 1091 & 12683 & & & 57931 & \\
\hline A69-1601-45307 & 376 & 0.095 & 376 & 0.095 & 3076 & 25323 & 3076 & 25323 & 125911 & 125911 \\
\hline A69-1601-45277 & 343 & 0.060 & 337 & 0.060 & 2926 & 29144 & 2439 & 21950 & 147554 & 107770 \\
\hline A69-1601-45279 & 304 & 0.086 & 304 & 0.086 & 2427 & 19535 & 2427 & 19535 & 86980 & 86980 \\
\hline A69-1601-45294 & 296 & 0.081 & 296 & 0.081 & 2084 & 27527 & 2084 & 27527 & 117299 & 117299 \\
\hline A69-1601-45297 & 230 & 0.082 & 230 & 0.082 & 1597 & 22161 & 1597 & 22161 & 99526 & 99526 \\
\hline A69-1601-45273 & 125 & 0.076 & 125 & 0.076 & 1025 & 33302 & 1025 & 33302 & 163916 & 163916 \\
\hline A69-1601-45308 & 111 & 0.049 & & & 966 & 12835 & & & 62171 & \\
\hline A69-1601-45323 & 159 & 0.085 & 159 & 0.085 & 1301 & 22793 & 1301 & 22793 & 118580 & 118580 \\
\hline A69-1601-45298 & 108 & 0.088 & 108 & 0.088 & 942 & 25013 & 942 & 25013 & 111363 & 111363 \\
\hline A69-1601-45275 & 5 & 0.000 & 5 & 0.000 & 191 & 10960 & 191 & 10960 & 50164 & 50164 \\
\hline A69-1601-45312 & 24 & 0.014 & 24 & 0.014 & 335 & 22601 & 335 & 22601 & 108430 & 108430 \\
\hline A69-1601-45280 & 13 & 0.047 & & & 93 & 18769 & & & 76599 & \\
\hline A69-9006-1700s & 40 & 0.046 & & & 270 & 13310 & & & 61367 & \\
\hline A69-1601-45309 & 47 & 0.070 & 47 & 0.070 & 310 & 16615 & 358 & 17343 & 79980 & 83495 \\
\hline
\end{tabular}

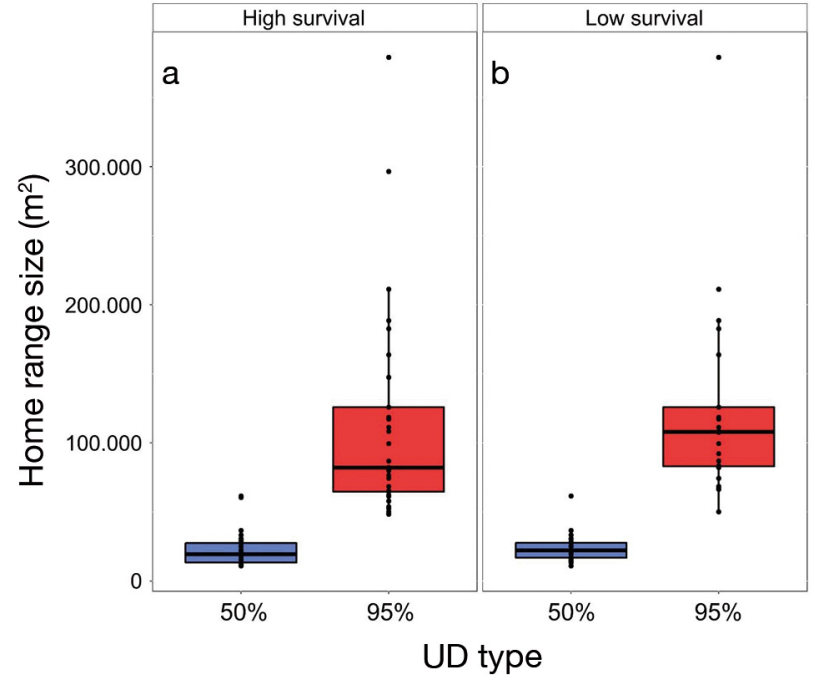

related in both low and high survival scenarios $(>0.97$ Pearson correlation coefficient); we therefore only tested for differences in $95 \%$ UD as a function of lionfish size and the time (days) spent within the array. For the high survival scenario, neither size nor time in the array significantly explained differences in $95 \%$

Fig. 5. Summaries of home range size (50 and $95 \%$ utilization distributions [UDs]) reported for (a) high and (b) low lionfish survival scenarios. Black points represent estimates for each individual. The distal ends of boxplot whiskers represent the smallest and largest values that are 1.5 times the inter-quartile range, the hinges (i.e. ends of boxes) represent the 25 th and 75th percentiles, and the inner horizontal line represents the median. There were no statistically significant differences between the 2 scenarios for both UD levels 

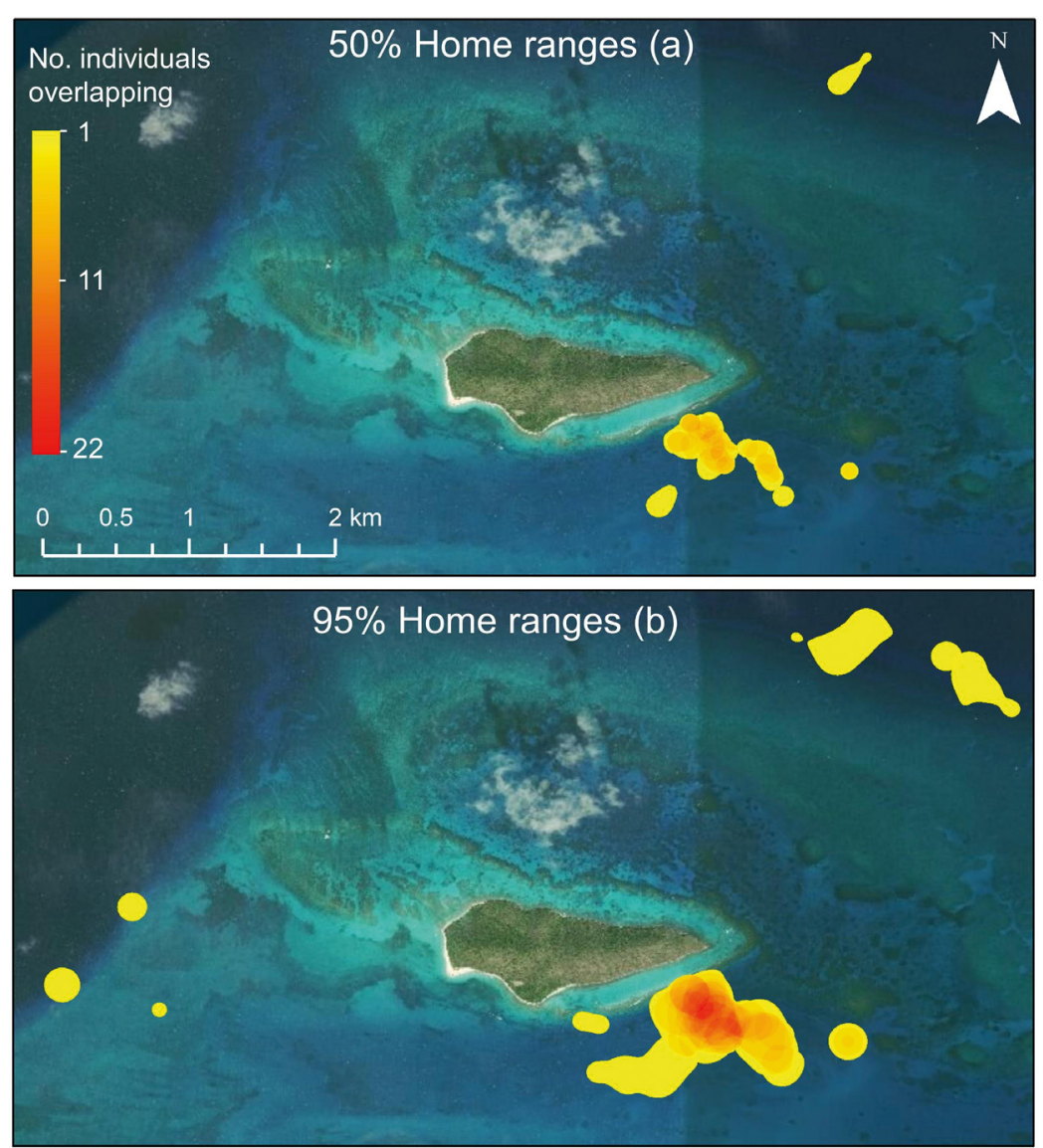

Fig. 6. Estimated (a) $50 \%$ and (b) $95 \%$ home ranges (utilization distributions) for individual lionfish tracked within BIRNM off St. Croix, USVI, based on the high survival scenario. The color gradient represents the number of individuals with overlapping home ranges

UD size, whereas the size of $95 \%$ UDs was positively associated with a greater number of days detected in the array for the low survival scenario $\left(F_{1,24}=2.519\right.$, $\mathrm{p}=0.020$; Fig. S4 in the Supplement).

\section{DISCUSSION}

Our study reveals that while home range size and maximum distance traveled by invasive lionfish can vary greatly among individuals, it is at least 3 times larger than the largest home range previously reported for the species (here, 0.379 versus $0.126 \mathrm{~km}^{2}$ of Bacheler et al. 2015; Table 1). Moreover, we found that lionfish travel greater distances than previously recorded. For example, Dahl \& Patterson (2020) found that the maximum distance traveled by lionfish across reef environments did not exceed $2 \mathrm{~km}$ (the spatial limit of their array), while we documented $\sim 40 \%$ of lionfish traveling $>1 \mathrm{~km}$ from their initial capture location during periods up to
$150 \mathrm{~d}$, and with a maximum cumulative distance of approximately $10 \mathrm{~km}$. Our results suggest that lionfish movement has been largely underestimated by past studies, likely due to constraints on the area over which previous visual tagging and acoustic studies have taken place, and the duration over which detections have been collected. The presence of a large acoustic array in BIRNM covering more than $35 \mathrm{~km}^{2}$ allowed us to complete the largest-scale examination of lionfish movement to date. Indeed, the full scale of a species' movement is only revealed by studying an area that exceeds its home range size over a period that captures important ontogenetic or seasonal shifts in habitat use, indicating the importance of maintaining large acoustic arrays. A growing number of telemetry studies are taking advantage of this array to study the movement ecology of species with varied life histories and trophic roles, including sea turtles, sharks, and barracuda. We suggest that future studies that incorporate native predators with similar ecologies to lionfish (e.g. groupers and moray eels) could shed additional light on the extent of spatial overlap and potential mechanisms governing competition with this invasive taxon.

Several features of our data and analyses increase our confidence that the long-distance movements we observed are attributed to lionfish movement, as opposed to movements by lionfish predators (i.e. a tagged fish being ingested and tag retained by predator). First, there is no evidence that average speeds (interpreted as the minimum distance traveled) during the movements exceeded estimates of lionfish swimming speed from previous work (e.g. Green et al. 2011). Second, we expect that transmitters would pass through the digestive system of a predator or be regurgitated relatively quickly. For example, Brunnschweiler (2009) estimated retention of hand-fed tags (placed inside a dead fish) larger than those used in this study to be between 0 and $17 \mathrm{~d}$ (mean $~ 8 \mathrm{~d}$ ) in 7 bull sharks Carcharinus leucas. Further, complete evacuation of food items from the stomach is estimated to take $<41 \mathrm{~h}$ in lemon sharks Negaprion brevirostris (Wetherbee et al. 1990). Yet following the 
long-distance movements observed in our study, we observed subsequent movements that extended past a $10 \mathrm{~d}$ period for at least 6 individuals, indicating that these tags were not stationary/expelled and were likely not within the gut of a predator. As described above, Dahl \& Patterson (2020) observed movements from tagged lionfish up to $2 \mathrm{~km}$ from tagging locations which showed no patterns of being predated. Incorporating transmitters with additional predation sensors (Weinz et al. 2020) would allow future studies to concretely distinguish between migration and predation events.

Van Beest et al. (2011) suggested factors that affect intraspecific home range variation included body mass, age, reproductive status, resource availability (e.g. for foraging), and temperature. Typically, home range size depends upon body mass as a function of metabolic rate, with larger individuals maintaining larger home ranges (Ofstad et al. 2016). In this study, fish size (TL) was not related to home range size or maximum distance traveled. However, our transmitters were limited to lionfish $>18 \mathrm{~cm}$ TL. Reproductive size for Caribbean lionfish is $10 \mathrm{~cm}$ TL for males and 18.9-19 cm TL for females (Morris 2009, Gardner et al. 2015). Given that all lionfish in our study were above this size, we may not have captured general differences in movement and home range between reproductive and immature portions of the population.

However, it is possible that the long-distance movements we observed are linked to individuals engaging in reproductive behavior, which can be sustained throughout the year in regions (such as St. Croix) when environmental conditions are favorable (Morris \& Whitfield 2009, Morris et al. 2011). In particular, cues for and constraints on reproduction related to variation in water temperature and day length across seasons are greatly dampened in lower latitude regions like the US Virgin Islands compared with sub-tropical reef environments occupied by the species in the Bahamas, Northern Gulf of Mexico, and US Atlantic coast. Reduced environmental variation (e.g. in terms of seawater temperature; range: $26.0-29.4^{\circ} \mathrm{C}$ ) in our study region may explain why we did not observe clear seasonal or lunar patterns relative to long-distance movements. Alternatively, it may be that the venomous dorsal spines of lionfish afford protection to size classes that would otherwise be more vulnerable to predation, reducing the potential for ontogenetic shifts in home range size seen in other reef fish species. Additional studies of movement involving similar large-scale, long-term tracking in higher latitude regions with greater seasonal environmental variation and in the species' home ranges, and advances in acoustic tagging technology facilitating inclusion of smaller individuals in tracking studies, would help us to begin testing these alternative hypotheses.

Variation in home range sizes and long-distance movements among lionfish may be partially explained by differences in the quality and structure of the habitat types used (Nemtzov 1997, Saïd et al. 2009). In other species, habitat quality has been shown to directly affect the size of an animal's home range, due to factors such as availability and competition for food resources (e.g. McLoughlin et al. 2000, Schradin et al. 2010). Approximately $60 \%$ of the fish tracked in this study were only detected in the main tagging area, and those that did move into adjacent habitats or made long-distance movements within the BIRNM array (Fig. 3) typically did so after several months of high residency. The continued use of this relatively large area $\left(\sim 0.5 \mathrm{~km}^{2}\right)$, often with high spatial overlap (e.g. up to 22 individuals, $95 \%$ UDs), suggests that adequate resources were available. Nevertheless, many individuals were not detected throughout the battery life of the transmitters, indicating either movements to areas outside the range of the receivers or mortality/predation events (see below). Therefore, there are likely additional drivers influencing habitat use in this study.

The majority of lionfish were tagged within patch reefs, which likely represent smaller pockets of highquality habitat (i.e. access to prey and shelter from predators) surrounded by unsuitable sandy habitat. Compared to continuous reef habitat, individuals inhabiting patch reefs may need to travel greater distances to access resources over time as they become limiting (Tamburello \& Côté 2015). The relatively low number of lionfish tagged on the fringing reef habitat with sufficient data to be included in the study ( 3 and 5 fish within low and high survival scenarios, respectively) compared to patch reefs (21 and 27 fish, respectively) precluded a thorough comparison of movement between the 2 groups. Nevertheless, home ranges (50\% UD, high survival) and rates of movement (high survival) were typically larger on patch reefs (mean values, respectively: $22884 \mathrm{~m}^{2}$ and $0.055 \mathrm{~m} \mathrm{~s}^{-1}$ ) compared to continuous reefs (mean values, respectively: $12874 \mathrm{~m}^{2}$ and $0.039 \mathrm{~m} \mathrm{~s}^{-1}$ ) supporting the possibility of limited resources on patch reefs.

Goodbody-Gringley et al. (2019) found a strong positive correlation, albeit influenced by water temperature, between lionfish density on mesophotic reefs and prey fish density and biomass. As a result, movement patterns may be driven more by prey abundance than competition and may also help explain why 
some individuals made long-distance movements towards the insular shelf and mesophotic reefs around BIRNM. Lionfish making these long-distance journeys either west or east around Buck Island to the insular shelf edge (Fig. 3) would pass through a variety of habitat types including seagrass meadows interspersed with sandy barrens, patch reef, hardbottom habitat dominated by large sponges, and high-profile patch reef. Further work is needed to quantify finescale habitat selection in this study area, as well as drivers of habitat connectivity and the mechanisms influencing large-scale movements.

Despite uncertainty in specific drivers of home range size and long-distance movements, there were clear patterns influencing lionfish activity. Rates of movement and acceleration estimates were highest during dawn and dusk periods. These periods often afford the greatest access to food (i.e. increased foraging activity) or may represent transitioning periods between resting and foraging locations (Green et al. 2011, Benkwitt 2016). McCallister et al. (2018) similarly found that acoustically tracked lionfish in the Florida Keys were most active during crepuscular periods. Lionfish are relatively inactive unless foraging (Green et al. 2011, Cure et al. 2012); therefore, increased activity during these periods is most likely due to peak foraging behavior. Diurnal and nocturnal locations are often different (McCallister et al. 2018, Dahl \& Patterson 2020), indicating that fish may transition between habitats, as a result of foraging bouts.

Water temperature also influenced activity patterns in this study, as demonstrated by its interaction with diel periods. Night activity trends relative to water temperature were often distinct from other diel periods; specifically, there appeared to be no influence of temperature on acceleration estimates and a negative influence of temperature on rates of movement. We hypothesize that these differences reflect the relative inactivity of lionfish during the night, resulting in less thermally coupled behaviors (Seymour 1982). By contrast, during periods when lionfish were more active (dawn, day, dusk), water temperature influenced physiological mechanisms and energetic budgeting of lionfish to a greater extent (e.g. Scott et al. 2017), leading to, for example, a positive relationship between acceleration estimates and water temperatures. More research investigating fine-scale space use patterns is needed to further understand the specific cues driving activity patterns.

We incorporated the possibility of tagged lionfish suffering a mortality event (or shed tag) via the low survival scenario to explore whether differences in interpretation of behavior resulted. This is a common concern in acoustic telemetry research, since $~ 50 \%$ of recent studies did not consider the possibility of mortality, although it is estimated to occur on average in at least $11 \%$ of tagged individuals (Klinard \& Matley 2020). Despite shorter detection periods for several individuals in the low survival scenario, comparisons of home range, rates of movement, and long-distance movements between scenarios typically only differed by small amounts (Table 4). This is not surprising given that individuals demonstrating restricted movements were consistently resident in the same area (i.e. high survival detections/individuals were not more mobile than low survival detections/individuals). We assumed that the high survival scenario would provide lower estimates of home range size and rates of movement since highly sedentary transmitters (potential shed tags or dead individuals) were included in the movement analyses. This trend was consistent with our prediction, but the differences were limited due to the reason explained above. Again, it is not clear which scenario best represented the detection history of living individuals, due to the resident nature of at least part of the lionfish population (Tamburello \& Côte 2015, Dahl \& Patterson 2020), as well as the relatively high detection range in the study area. However, estimates of high and low survival scenarios for more mobile species might produce

Table 4. Comparison of high and low survival scenarios for the home range and movement metrics quantified in this study; ns: not statistically significant at $\alpha=0.05$. ROM: rate of movement; UD: utilization distribution

\begin{tabular}{|c|c|c|c|}
\hline Variable & $\begin{array}{c}\text { High } \\
\text { survival }\end{array}$ & $\begin{array}{c}\text { Low } \\
\text { survival }\end{array}$ & $\begin{array}{c}\text { High vs. } \\
\text { Low } \\
\text { result }\end{array}$ \\
\hline Number of fish & 32 & 23 & $\mathrm{H}>\mathrm{L}$ \\
\hline Number of detections & 1417695 & 1005667 & $\mathrm{H}>\mathrm{L}$ \\
\hline Mean residency index & $0.86 \pm 0.23$ & $0.92 \pm 0.16$ & $\mathrm{H}<\mathrm{L}$ \\
\hline Mean rate of movement $\left(\mathrm{m} \mathrm{s}^{-1}\right)$ & $0.051 \pm 0.027$ & $0.063 \pm 0.025$ & $\mathrm{H}<\mathrm{L}$ \\
\hline Effect of diel period on ROM & $\mathrm{p}<0.001$ & $\mathrm{p}<0.001$ & $\mathrm{H}=\mathrm{L}$ \\
\hline Effect of temperature on ROM & $\mathrm{p}<0.001$ & $\mathrm{p}<0.001$ & $\mathrm{H}=\mathrm{L}$ \\
\hline $50 \%$ UD Home range $\left(\mathrm{min}_{i} \mathrm{~m}^{2}\right)$ & 10959 & 10959 & $\mathrm{H}=\mathrm{L}$ \\
\hline $50 \%$ UD Home range $\left(\max _{i} \mathrm{~m}^{2}\right)$ & 61668 & 61668 & $\mathrm{H}=\mathrm{L}$ \\
\hline $50 \%$ UD home range $\left(\right.$ mean; $\left.\mathrm{m}^{2}\right)$ & 21320 & 23848 & $\mathrm{H}<\mathrm{L}, \mathrm{ns}$ \\
\hline $95 \%$ UD Home range $\left(\mathrm{min}_{;} \mathrm{m}^{2}\right)$ & 48373 & 50164 & $\mathrm{H}<\mathrm{L}$ \\
\hline $95 \%$ UD Home range $\left(\max _{i} \mathrm{~m}^{2}\right)$ & 379163 & 379163 & $\mathrm{H}=\mathrm{L}$ \\
\hline $95 \%$ UD Home range (mean; $\mathrm{m}^{2}$ ) & 105588 & 121512 & $\mathrm{H}<\mathrm{L}, \mathrm{ns}$ \\
\hline Effect of fish size on $95 \%$ UD & ns & ns & $\mathrm{H}=\mathrm{L}$ \\
\hline Effect of no. days on $95 \%$ UD & ns & $\mathrm{p}<0.02$ & $\mathrm{H}<\mathrm{L}$ \\
\hline
\end{tabular}


more distinct differences among survival scenarios. Regardless, these estimates provide lower and upper ranges in values for ecologically relevant behavioral metrics for future comparison, and do not bias findings of long-distance movements.

We suggest that lionfish control programs could benefit substantially from accounting for maximum lionfish home range size, movement rates, and patterns of directional movement in identifying the location and spatial coverage of target areas for culling. In particular, high rates of recolonization have been reported in studies of lionfish removal on reefs that are larger than the majority of previous home range estimates (i.e. $2500 \mathrm{~m}^{2}$; Green et al. 2015) and spaced apart at distances greater than early estimates of movement for the species (i.e. $>500 \mathrm{~m}_{i}$ Smith et al. 2017). Our study shows that lionfish home range is highly variable, but likely far greater than estimated previously, confirming that local management (in terms of culling) is likely to be affected by recolonization from adjacent reefs. Thus, considering the spatial arrangement and size of focal habitats could assist in limiting recolonization following population control, for example by targeting culling activities over priority areas that are least the size of the mean home range estimated in our study (i.e. $101000 \mathrm{~m}^{2}$ or $\sim 10 \mathrm{ha}$ ), or at sites that are isolated from other habitats by the radius of circular home range of this size (i.e. $~ 180 \mathrm{~m}$ ). The relatively common occurrence of long-distance dispersal by mature lionfish of up to $10 \mathrm{~km}$ within a $10 \mathrm{~d}$ period also highlights additional management obstacles, as new habitats appear to be readily explored by at least a portion of individuals occupying a region. Most long-distance movements by lionfish in this study represent transit from shallow reef tagging areas to deeper sites at the edge of the continental shelf and mesophotic reefs in BIRNM, with no evidence of individuals moving back into shallow areas over the 14 mo study period. While we are not able to ascertain whether fish also move from deep habitats into shallow areas, net movement from deep to shallow would suggest that culling frequency may need to be even higher to sufficiently suppress densities in these areas as a result of migration from other habitats.

Acknowledgements. We thank the many volunteer divers who helped complete field work for this project: Marcia Taylor, Jack Downes, Michael Funk, Kim Gillespie, Norm Gustafson, Mareike Duffing-Romero, Bonnie Barnes, and Gabby Magalski. We thank our partners, especially Zandy Hillis-Starr, at the National Park Service for permits to work within park boundaries and providing downloaded data for the study. Thanks to NPS Bio Sci Techs Nathaniel Hanna Holloway and Tessa Code for assistance with telemetry data downloading and transfer. We also thank Caribbean Sea Adventures, St. Croix Ultimate Bluewater Adventures (SCUBA), and Dive Experience logistic and personnel support for this research. Funding for this research was provided by the Virgin Islands Established Program to Stimulate Competitive Research (VI-EPSCoR) through NSF Grant 1355437, Gulf Research Program Disaster Recovery Grant 2000009518, NSERC Discovery Grant RGPIN-2018-05712, and an Association of Marine Laboratories of the Caribbean student-in-aid grant. This research was conducted under UVI Institutional Animal Care and Use Committee permit 949107 and National Park Service research permits BUIS00072 and BUIS-2016-SCI-0004. This is contribution number 234 from the University of the Virgin Islands, Center for Marine and Environmental Studies. R code for our movement and home range analyses are available at https:// github.com/CHANGE-Lab.

\section{LITERATURE CITED}

Akins JL, Morris JA, Green SJ (2014) In situ tagging technique for fishes provides insight into growth and movement of invasive lionfish. Ecol Evol 4:3768-3777

Albins MA (2013) Effects of invasive Pacific red lionfish Pterois volitans versus a native predator on Bahamian coral-reef fish communities. Biol Invasions 15:29-43

Albins MA (2015) Invasive Pacific lionfish Pterois volitans reduce abundance and species richness of native Bahamian coral-reef fishes. Mar Ecol Prog Ser 522:231-243

*Bacheler NM, Whitfield PE, Muñoz RC, Harrison BB, Harms CA, Buckel CA (2015) Movement of invasive adult lionfish Pterois volitans using telemetry: importance of controls to estimate and explain variable detection probabilities. Mar Ecol Prog Ser 527:205-220

* Becker SL, Finn JT, Danylchuk AJ, Pollock CG, Hillis-Starr Z, Lundgren I, Jordaan A (2016) Influence of detection history and analytical tools on quantifying spatial ecology of a predatory fish in a marine protected area. Mar Ecol Prog Ser 562:147-161

Benkwitt CE (2015) Non-linear effects of invasive lionfish density on native coral-reef fish communities. Biol Invasions 17(5):1383-1395

Benkwitt CE (2016) Invasive lionfish increase activity and foraging movements at greater local densities. Mar Ecol Prog Ser 558:255-266

* Bivand R, Lewin-Koh N (2019) maptools: Tools for handling spatial objects. R package version 0.9-5. https://CRAN. R-project.org/package $=$ maptools

Bolden SK (2000) Long-distance movement of a Nassau grouper (Epinephelus striatus) to a spawning aggregation in the central Bahamas. Fish Bull 98:642-645

*Börger L, Dalziel BD, Fryxell JM (2008) Are there general mechanisms of animal home range behavior? A review and prospects for future research. Ecol Lett 11:637-650

Brunnschweiler JM (2009) Tracking free-ranging sharks with hand-fed intra-gastric acoustic transmitters. Mar Freshw Behav Physiol 42:201-209

Calenge C (2006) The package adehabitat for the R software: a tool for the analysis of space and habitat use by animals. Ecol Model 197: 516-519

Chagaris D, Binion-Rock S, Bogdanoff A, Dahl K and others (2017) An ecosystem-based approach to evaluating impacts and management of invasive lionfish. Fisheries 42 : 421-431 
Côté IM, Smith NS (2018) The lionfish Pterois sp. invasion: Has the wo rst-case scenario come to pass? J Fish Biol 92: 660-689

Côté IM, Green SJ, Hixon MA (2013) Predatory fish invaders: insights from Indo-Pacific lionfish in the western Atlantic and Caribbean. Biol Conserv 164:50-61

Cure K, Benkwitt CE, Kindinger TL, Pickering EA, Pusack TJ, McIlwain JL, Hixon MA (2012) Comparative behavior of red lionfish Pterois volitans on native Pacific versus invaded Atlantic coral reefs. Mar Ecol Prog Ser 467:181-192

Dahl KA, Patterson WF (2020) Movement, home range, and depredation of invasive lionfish revealed by fine-scale acoustic telemetry in the northern Gulf of Mexico. Mar Biol 167:1-22

Gardner PG, Frazer TK, Jacoby CA, Yanong RP (2015) Reproductive biology of invasive lionfish (Pterois spp.). Front Mar Sci 2:7

Goodbody-Gringley G, Eddy C, Pitt JM, Chequer AD, Smith SR (2019) Ecological drivers of invasive lionfish (Pterois volitans and Pterois miles) distribution across mesophotic reefs in Bermuda. Front Mar Sci 6:258

Green SJ, Grosholz ED (2021) Functional eradication as a framework for invasive species control. Front Ecol Environ 19:98-107

* Green SJ, Akins JL, Côté IM (2011) Foraging behaviour and prey consumption in the Indo-Pacific lionfish on Bahamian coral reefs. Mar Ecol Prog Ser 433:159-167

* Green SJ, Dulvy NK, Brooks AM, Akins JL, Cooper AB, Miller S, Côté IM (2014) Linking removal targets to the ecological effects of invaders: a predictive model and field test. Ecol Appl 24:1311-1322

Green SJ, Castillo B, Reale-Munroe K, Lundgren IF, Pollock CG, Akins JL (2015) Predicting and testing ecological thresholds for invasive lionfish control in Buck Island Reef National Monument. US National Park Service Report BUIS-2011-SCI-0007

*Gaen SJ, Underwood EB, Akins JL (2017) Mobilizing volunteers to sustain local suppression of a global marine invasion. Conserv Lett 10:726-735

*Hamilton RJ, Adams S, Choat JH (2008) Sexual development and reproductive demography of the green humphead parrotfish (Bolbometopon muricatum) in the Solomon Islands. Coral Reefs 27:153-163

Hays GC, Bailey H, Bograd SJ, Bowen WD and others (2019) Translating marine animal tracking data into conservation policy and management. Trends Ecol Evol 34:459-473

* Hixon MA, Green SJ, Albins MA, Akins JL, Morris JA Jr (2016) Lionfish: a major marine invasion. Mar Ecol Prog Ser 558:161-165

Jud ZR, Layman CA (2012) Site fidelity and movement patterns of invasive lionfish, Pterois spp., in a Florida estuary. J Exp Mar Biol Ecol 414-415:69-74

Kessel ST, Cooke SJ, Heupel MR, Hussey NE, Simpfendorfer CA, Vagle S, Fisk AT (2014) A review of detection range testing in aquatic passive acoustic telemetry studies. Rev Fish Biol Fish 24:199-218

Klinard NV, Matley JK (2020) Living until proven dead: addressing mortality in acoustic telemetry research. Rev Fish Biol Fish 30:485-499

Kyne FK, Chapman JK, Green SJ, Simmons AL, Gough CLA (2020) Managing invasive lionfish in Belize's Marine Protected Areas. Blue Ventures Conservation Report. https://blueventures.org/publication/managing-invasivelionfish-in-belizes-marine-protected-areas/ (accessed on 2 October 2020)
Lazaridis E (2014) lunar: Lunar phase \& distance, seasons and other environmental factors. $\mathrm{R}$ package version 0.1-04. http://statistics.lazaridis.eu

*Lennox RJ, Blouin-Demers G, Rous AM, Cooke SJ (2016) Tracking invasive animals with electronic tags to assess risks and develop management strategies. Biol Invasions 18:1219-1233

Lesser MP, Slattery M (2011) Phase shift to algal dominated communities at mesophotic depths associated with lionfish (Pterois volitans) invasion on a Bahamian coral reef. Biol Invasions 13:1855-1868

* McCallister M, Renchen J, Binder B, Acosta A (2018) Diel activity patterns and movement of invasive lionfish (Pterois volitans/P. miles) in the Florida Keys identified using acoustic telemetry. Gulf Caribb Res 29:27-40

*McLoughlin P, Ferguson S, Messier F (2000) Intraspecific variation in home range overlap with habitat quality: a comparison among brown bear populations. Evol Ecol 14:39-60

Minns CK (1995) Allometry of home range size in lake and river fishes. Can J Fish Aquat Sci 52:1499-1508

Morris JA Jr (2009). The biology and ecology of the invasive Indo-Pacific lionfish. $\mathrm{PhD}$ dissertation, North Carolina State University, Raleigh, NC

Morris JA Jr, Whitfield PE (2009) Biology, ecology, control and management of the invasive Indo-Pacific lionfish: an updated integrated assessment. Tech Memo NOS NCCOS 99. NOAA, Silver Springs, MD

Morris JA Jr, Sullivan CV, Govoni JJ (2011) Oogenesis and spawn formation in the invasive lionfish, Pterois miles and Pterois volitans. Sci Mar 75:147-154

Nemeth RS (2009) Dynamics of reef fish and decapod crustacean spawning aggregations: underlying mechanisms, habitat linkages and trophic interactions. In: Nagelkerken I (ed) Ecological connectivity among tropical coastal ecosystems. Springer, Dordrecht, p 73-134

Nemeth RS (2012) Ecosystem aspects of spawning aggregations. In: Sadovy de Mitcheson Y, Colin P (eds) Reef fish spawning aggregations: biology, research and management. Springer, Dordrecht, p 21-56

Nemtzov SC (1997) Intraspecific variation in home range exclusivity by female green razorfish, Xyrichtys splendens (family Labridae), in different habitats. Environ Biol Fishes 50:371-381

Ofstad EG, Herfindal I, Solberg EJ, Sæther BE (2016) Home ranges, habitat and body mass: simple correlates of home range size in ungulates. Proc R Soc B 283:20161234

* Pinheiro J, Bates D, DebRoy S, Sarkar D, R Core Team (2019) _nlme: linear and nonlinear mixed effects models. R package version, 3.1-142. https://CRAN.R-project.org/ package $=$ nlme

Pittman SJ, Hile SD, Jeffrey CFG, Caldow C, Kendall MS, Monaco ME, Hillis-Starr Z (2008) Fish assemblages and benthic habitats of Buck Island Reef National Monument (St. Croix, US Virgin Islands) and the surrounding seascape: a characterization of spatial and temporal patterns. NOAA Tech Memo NOS NCCOS 71. NOAA, Silver Spring, MD

R Core Team (2019) R: a language and environment for statistical computing. R Foundation for Statistical Computing, Vienna

Raymond WW, Albins MA, Pusack TJ (2015) Competitive interactions for shelter between invasive Pacific red lionfish and native Nassau grouper. Environ Biol Fishes 98: $57-65$ 
Rhodes KL, McIlwain J, Joseph E, Nemeth RS (2012) Reproductive movement, residency and fisheries vulnerability of brown-marbled grouper, Epinephelus fuscoguttatus (Forsskål, 1775). Coral Reefs 31:443-453

Saïd S, Gaillard JM, Widmer O, Débias F, Bourgoin G, Delorme D, Roux C (2009) What shapes intra-specific variation in home range size? A case study of female roe deer. Oikos 118:1299-1306

Schofield PJ (2010) Update on geographic spread of invasive lionfishes (Pterois volitans [Linnaeus, 1758] and $P$. miles [Bennett, 1828]) in the Western North Atlantic Ocean, Caribbean Sea and Gulf of Mexico. Aquat Invasions 5(Suppl 1):S117-S122

Schofield PJ, Akins L (2019) Non-native marine fishes in Florida: updated checklist, population status and early detection/rapid response. BioInvasions Rec 8:898-910

Schradin C, Schmohl G, Rödel HG, Schoepf I and others (2010) Female home range size is regulated by resource distribution and intraspecific competition: a long-term field study. Anim Behav 79:195-203

Scott M, Heupel M, Tobin A, Pratchett M (2017) A large predatory reef fish species moderates feeding and activity patterns in response to seasonal and latitudinal temperature variation. Sci Rep 7:12966

Selby TH, Hart KM, Fujisaki I, Smith BJ and others (2016) Can you hear me now? Range-testing a submerged passive acoustic receiver array in a Caribbean coral reef habitat. Ecol Evol 6:4823-4835

Semmens BX, Buhle ER, Salomon AK, Pattengill-Semmens CV (2004) A hotspot of non-native marine fishes: evidence for the aquarium trade as an invasion pathway. Mar Ecol Prog Ser 266:239-244

Seymour RS (1982) Physiological adaptations to aquatic life. In: Gans C, Pough FH (eds) Biology of the Reptilia, Vol 13. Academic Press, London, p 1-51

Simpfendorfer CA, Heupel MR, Hueter RE (2002) Estimation of short-term centers of activity from an array of omnidirectional hydrophones and its use in studying animal movements. Can J Fish Aquat Sci 59:23-32

Editorial responsibility: Tim McClanahan,

Mombasa, Kenya

Reviewed by: E. Guerra-Castro and 2 anonymous referees
Simpfendorfer CA, Huveneers C, Steckenreuter A, Tattersall K, Hoenner X, Harcourt R, Heupel MR (2015) Ghosts in the data: false detections in VEMCO pulse position modulation acoustic telemetry monitoring equipment. Anim Biotelemetry 3:1-10

Smith NS, Green SJ, Akins JL, Miller S, Côté IM (2017) Density-dependent colonization and natural disturbance limit the effectiveness of invasive lionfish culling efforts. Biol Invasions 19:2385-2399

Sutherland WJ, Clout M, Côté IM, Daszak P and others (2010) A horizon scan of global conservation issues for 2010. Trends Ecol Evol 25:1-7

Tamburello N, Côté IM (2015) Movement ecology of IndoPacific lionfish on Caribbean coral reefs and its implications for invasion dynamics. Biol Invasions 17:1639-1653

*USGS (2019) United States Geological Survey Nonindigenous Aquatic Invasive Species Database. http://nas.er. usgs.gov

*van Beest FM, Rivrud IM, Loe LE, Milner JM, Mysterud A (2011) What determines variation in home range size across spatiotemporal scales in a large browsing herbivore? J Anim Ecol 80:771-785

Wetherbee BM, Gruber SH, Cortés E (1990) Diet, feeding habits, digestion, and consumption in sharks, with special reference to the lemon shark, Negrapion brevirostris. In: Pratt HI Jr, Gruber SH, Taniuchi T (eds) Elasmobranchs as living resources: advances in the biology, ecology, systematics, and the status of the fisheries. NOAA Tech Rep NMFS 90:29-47

Weinz AA, Matley JK, Klinard NV, Fisk AT, Colborne SF (2020) Identification of predation events in wild fish using novel acoustic transmitters. Anim Biotelem 8:28

*Whitfield PE, Gardner T, Vives SP, Gilligan MR, Courtenay WR Jr, Ray GC, Hare JA (2002) Biological invasion of the Indo-Pacific lionfish Pterois volitans along the Atlantic coast of North America. Mar Ecol Prog Ser 235:289-297

*Woolnough DA, Downing JA, Newton TJ (2009) Fish movement and habitat use depends on water body size and shape. Ecol Freshw Fish 18:83-91

Submitted: December 7, 2020

Accepted: July 1, 2021

Proofs received from author(s): August 30, 2021 